\title{
Comparabilidade de corpora díspares em Antroponomástica Comparada
}

\author{
Márcia Sipavicius Seide ${ }^{1}$
}

1 Professora Associada da Unioeste, orientadora de Mestrado e Doutorado do Programa de Pós-Graduação em Letras da UNIOESTE, docente do PPGL, campus de Cascavel e do Colegiado de Letras, campus de Marechal Cândido Rondon, Brasil. E-mail: marciaseda4@hotmail.com

RESUMO: O objetivo deste artigo é verificar se há suficiente convergência de resultados de amostras de nomes de tamanhos diferentes para que possam ser utilizados em pesquisas de Antroponomástica Comparada. Para tanto, o comportamento de um conjunto de dezessete antropônimos em duas amostras de um mesmo universo formado pela população do Município paranaense de Marechal Cândido Rondon foi comparado. Enquanto a primeira foi constituída pelos cem primeiros nomes dos recém-nascidos registrados em cinco anos (1960, 1970, 1980, 1990 e 2000) totalizando 500 nomes, a segunda corresponde aos dados do IBGE relativos aos nomes dos residentes no Município por década de nascimento dos mesmos. Não obstante a diferença existente entre as amostras, a convergência de resultados legitima o uso de corpora díspares para análise comparativa de tendências gerais desde que sejam feitas ressalvas quanto à datação precisa de início e fim dessas tendências.

Palavras-chave: Onomástica; pesquisa quantitativa; metodologia.

\section{Comparability of disparate corpora in Comparative Antroponomastics}

ABSTRACT The aim of this paper is to verify if there is enough convergence of results of samples of names of different sizes so that they can be used in Comparative Anthroponomastics research. the behavior of a set of seventeen anthroponyms in two samples of the same universe formed by the population of the Paraná municipality of Marechal Cândido Rondon was compared. While the first one is made up of the first hundred names of newborns registered in five years (1960, 1970, 1980, 1990 and 2000) totaling 500 names, the second corresponds to the IBGE data regarding the names of residents in the municipality per decade of their birth. Despite the differences of the samples, the convergence of results legitimizes the use of disparate corpora for comparative analysis of general trends provided that caveats are made as to the precise date of beginning e end of these tendencies.

Keywords: Onomastics; quantitative research; methodology.

\section{INTRODUÇÃO}

A Onomástica é uma área de pesquisa interdisciplinar que se volta ao estudo dos nomes próprios, no interior da qual está a Antroponomástica, que se dedica exclusivamente aos nomes próprios de pessoas que constituem um conjunto heterogênero não obstante todos compartilharem a função pragmática de fazer referência a um ser único. Neste artigo foca-se o prenome que corresponde ao nome oficial do indivíduo registrado em documentos oficiais antes de seu sobrenome, este último responsável por distinguir o indivíduo de outros que portam o mesmo prenome, de um lado, e, de outro, indicar sua genealogia.

Em artigo de revisão de literatura (SEIDE, 2016), apresentam-se diversas subáreas da Antroponomástica, entre as quais destaco a Antroponomástica Comparada, sub-área cujas investigações têm por objetivo comparar dois ou mais sistemas antroponímicos, os quais se constituem pela totalidade 
de nomes próprios de pessoas (antropônimos) utilizados numa comunidade linguística e possibilidades de utilização desses nomes. Dos 33 artigos avaliados em sua revisão de literatura, apenas quatro estavam inseridos na Antroponomástica Comparada, a saber: Ruiz (2014), Gudurić (2014), Mutsukawa (2014) e López-Franco (2014a).

No primeiro artigo referenciado acima, Ruiz teve por objetivo comparar um mesmo campo semântico de prenomes em seis línguas, a saber: náhuatl, omaya e o purépecha, o grego, o latim e o hebraico. Para tanto elaborou um corpus diminuto formado por nomes citados em dicionários de nomes etimológicos nos idiomas supramencionados sem nenhuma preocupação estatística ou quantitativa, mas meramente com o propósito de evidenciar a existência do campo semântico antroponímico nos idiomas considerados.

Mutsukawa (2014), por sua vez, sintetizou pesquisas já publicadas sobre as características fonológicas e semânticas de prenomes atribuídos a homens e prenomes atribuídos a mulheres em dois idiomas: o japonês e inglês. Cada uma das pesquisas relatadas utilizou corpus de dados coletados em fontes diferentes e de diferentes tamanhos. Não obstante tais discrepâncias, - autor reuniu os resultados alcançados para chegar a conclusões sobre a caracterização linguística dos prenomes em cada idioma.

Com o propósito de avaliar como nomes próprios franceses são adaptados ao idioma sérvio, Gudurić (2014) analisou um corpus formado por textos escritos em sérvio e traduzidos da língua francesa para a língua sérvia formado por "Le corpus présenté dans ce texte est extrait des journaux, des émissions radio et télévisées, des traducti- ons simultanées et consécutives faites à des occasions différentes (fêtes, compétitions sportives, visites officielles des fonctionnaires)" (GUDURIĆ, 2014, p.327) ${ }^{1} .0$ pesquisador contudo, não informou o tamanho do corpus nem como foi feita a amostragem.

Mais precisa do ponto de vista quantitativo, é a pesquisa reportada por LópezFranco (2014). Em sua pesquisa, ela comparou a atribuição antroponímica em 1970 e 1975 em duas localidades, Montepellier, na França e Tlatnepantla de Baz, no México. A pesquisa dela foi realizada tendo por base dois corpora de tamanhos semelhantes formado por nomes registrados em Certidões de Nascimento, a saber: 6.203 lavradas na primeira cidade citada e 6203 na segunda ao todo e, para os anos citados, respectivamente 880 e 898 nomes. Apesar de o tamanho do corpus ser semelhante, talvez não o seja a sua representatividade, tendo em vista que a população da cidade francesa é maior que o da cidade mexicana: enquanto, em 2010, havia mais de 600.000 habitantes na primeira cidade, na segunda, em 2012, havia pouco mais de 400.00 habitantes (LÓPEZ-FRANCO, 2014b).

Para Huschka e Wagner (2010), a dimensão da amostra influencia a distribuição dos nomes, motivo pelo qual é necessário equalizar o tamanho dos corpora para torná-los comparáveis, se bem alertem para a possibilidade de haver erros de amostragem: "<<Sampling error >> means that, due to the process that generates a sample of a larger "universe"(e.g., all citizens in a country), a sample cannot be an exact mirror of this

\footnotetext{
1 "estratos de jornais, emissões de rádio e de televisão e traduções simultâneas e consecutivas feita em várias ocasiões (festas, competições esportivas, visitas oficiais de funcionários" (Tradução nossa)
} 
universe"

(HUSCHKA;

WAGNER, 2010,p.22). Seguindo-se as recomendações de Huschka e Wagner (2010), da área da Economia, haveria menos erros quando se comparam amostras de tamanhos parecidos de universos cujas dimensões fossem igualmente semelhantes. Considerando-se que os países e as várias comunidades que podem habitar um país são, na maioria das vezes, díspares do ponto de vista populacional, tais exigências levariam a análises comparativas de universos de antemão semelhantes e dificultariam a validação de pesquisas comparativas mais amplas que pudessem abranger a diversidade populacional da maioria dos países.

O paradoxo acima descrito motivou a realização da pesquisa ora descrita na qual são comparados os comportamentos de nomes em corpora díspares. Foram comparados os resultados de duas pesquisas: a realizada por Seide (2013), tendo por base uma amostra de Certidões de Nascimento lavradas no Município de Marechal Cândido Rondon, situado na região oeste do Estado do Paraná, nas décadas de 1960 a 2000 totalizando 500 nomes que correspondem a cerca de $1,07 \%$ da população atual do $\mathrm{Mu}$ nicípio e a publicada pelo IBGE com base no Censo Demográfico 2010 (2017), baseada em amostra estatística de nomes de residentes no mesmo Município.

Ressalto como as amostras são diferentes entre si. No primeiro caso, amostra de Certidão de Nascimento e, no segundo, de informações fornecidas por residentes adultos. Nada garante que uma pessoa que re-

2 " $<<$ erros de amostragem $>>$ significam que, devido ao processo que gera uma amostra de um <<universo〉> maior (e.g., todos cidadãos de um país), uma amostra pode não ser um espelho exato desse universo" (Tradução nossa) sida no Município também tenha sido registrada no mesmo local e, ao contrário, uma pessoa nascida ou registrada no Município pode não residir nele. Enquanto no IBGE os nomes foram agrupados por décadas conforme a data de nascimento dos entrevistados em 2010, na outra pesquisa foi considerada somente uma parcela dos indivíduos registrados no cartório do Município em cada ano (os cem primeiros registrados em 1960, 1970, 1980, 1990 e 2000).

Durante o período estudado, a população do Município acompanhou o crescimento demográfico da região oeste do $\mathrm{Pa}$ raná, a qual recebeu muitos migrantes como resultado da política de colonização da região proposta por Getúlio Vargas e implementada a partir de 1960, conhecida como Marcha para o Oeste:

As taxas de crescimento e urbanização da Mesorregião Oeste do Paraná evoluíram bastante entre 1960 e 2000, período em que a população total, de acordo com os respectivos Censos Demográficos, passou de 135.677 para 1.138 .582 pessoas. Isso se deveu a alguns fatores peculiares a esse espaço regional e a outros, que também afetaram o interior do Brasil, principalmente, de um modo geral. Aos primeiros podem ser relacionadas à construção da Ponte da Amizade em Foz do Iguaçu, à reestruturação e pavimentação da BR277 e, especialmente, à construção da Usina Hidrelétrica de Itaipu e, por conseguinte, o alagamento de seu reservatório. Aos fatores mais gerais, pode-se associar a modernização agrícola e, em corolário, a concentração da estrutura fundiária. (REOLON, 2007, p.53)

Uma vez que o incremento populacional foi devido, principalmente, à chegada de 
migrantes, a investigação ora apresentada partiu do pressuposto de que os residentes recenseados pelo IBGE em 2010 representam o resultado desse fluxo migratório, mais do que o aumento populacional devido à taxa de natalidade no período. Foi presumido que os nomes da amostra do IBGE representam os nomes disponíveis na região, nomes da população de crianças e de adultos que moram no Município. Como a amostra de Seide (2013) foi feita a partir da coleta de Certidões de Nascimento, pressupus que os nomes coletados representam os nomes dos nascidos da região, indiciando, pois, a escolha antroponímica dos pais.

Esta comparação foi feita com o objetivo de investigar se haveria ou não convergência nos resultados, isto é, se em ambas, um mesmo prenome teria períodos idênticos ou aproximados (até uma década antes ou depois) de auge e declínio de utilização.

O presente artigo está organizado em uma única seção seguida das considerações finais na qual explicita-se o significado onomástico dos resultados alcançados e as contribuições da pesquisa experimental realizada.

\section{ANÁLISE COMPARATIVA DAS AMOSTRAS}

Com base na listagem dos nomes da amostra de Certidões de Nascimento, doze nomes masculinos foram escolhidos aleatoriamente para a análise comparativa: Adriano, Alexandre, Anderson, André, Augusto, Carlos, Diego, Gabriel, Jean, Jonatan, José, Lucas, Marcelo, Marcel, Márcio, Rodrigo e Vinicius.

Dada a disparidade de número de ocorrência em cada corpus, para cada ocorrência do corpus de Certidões de Nascimento foram atribuídos 10 pontos. Mediante este procedimento foi possível visualizar, mediante gráficos, o comportamento em ambos os corpora. Além disso, considerou-se apenas o primeiro nome pois, quando uma pessoa recebe dois nomes, a pesquisa do IBGE considerou apenas o primeiro nome informado. Em todos os gráficos apresentados, a curva vermelha corresponde ao corpus de Seide (2013) e a linha azul ao corpus do IBGE (2010) cujos gráficos foram elaborados novamente informando-se os valores indicados nos gráficos gerados automaticamente no site do IBGE. Com base nas comparações entre as curvas, foi avaliado se havia ou convergência dos resultados para se verificar a comparabilidade de corpora díspares.

Para o prenome Carlos, na amostra do IBGE, há registro de continuidade de uso durante todas as décadas com pouca variação entre elas: em 1960, havia 44 portadores do nome nascidos, em 1970, 38 portadores, e, em 1980, 46 portadores. No corpus de Seide (2013), contudo, o nome não apresentou os mesmos índices de utilização. O comportamento do nome Carlos, na amostra de Seide (2013), mostra que, como nomes de recém-nascidos, o auge de atribuição ocorreu nas décadas de 1960 e 1970, não sendo mais utilizado depois disso. Neste caso houve divergência de resultados devido a possível falha de amostragem devido à baixa representatividade da amostra de Certidões de Nascimento ou a possibilidade de muito dos portadores do nome Carlos serem residentes que foram morar no Município durante o período contemplado. 
Gráfico 1 - Comparação dos resultados para o nome Carlos Graph 1 -Comparison of results for the name Carlos

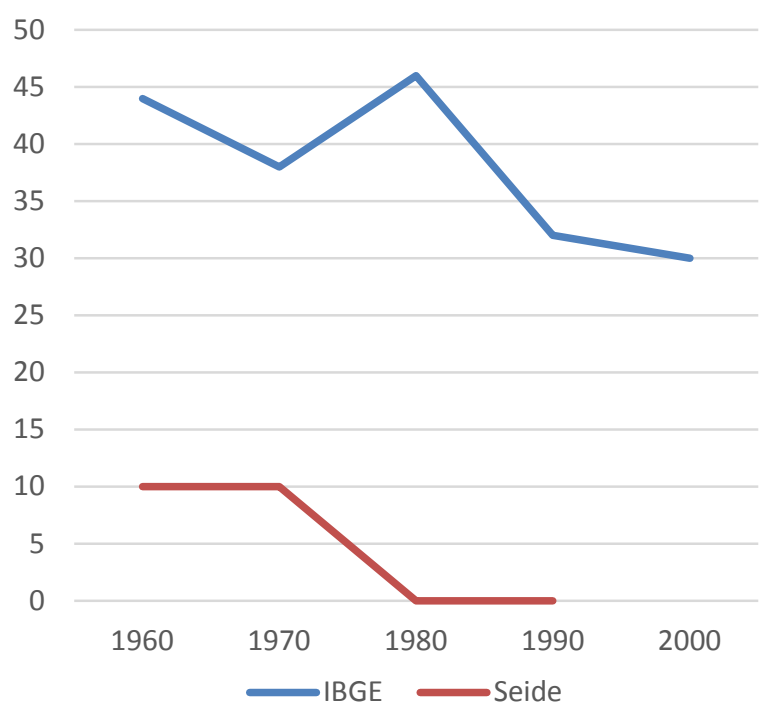

O prenome José, por sua vez, apresentou decréscimo de utilização em ambos os corpora, porém, como nome de recém-nascido registrado no Município, na amostra, deixou de ser usado na década de 1980, como nome de residente, o decréscimo começou antes, na década de 1960. Há para este nome uma divergência parcial, todavia, a tendência de decréscimo de utilização do nome foi registrada em ambos.

Gráfico 2 - Comparação de resultados para o nome José Graph 2 - Comparison of results for the name José

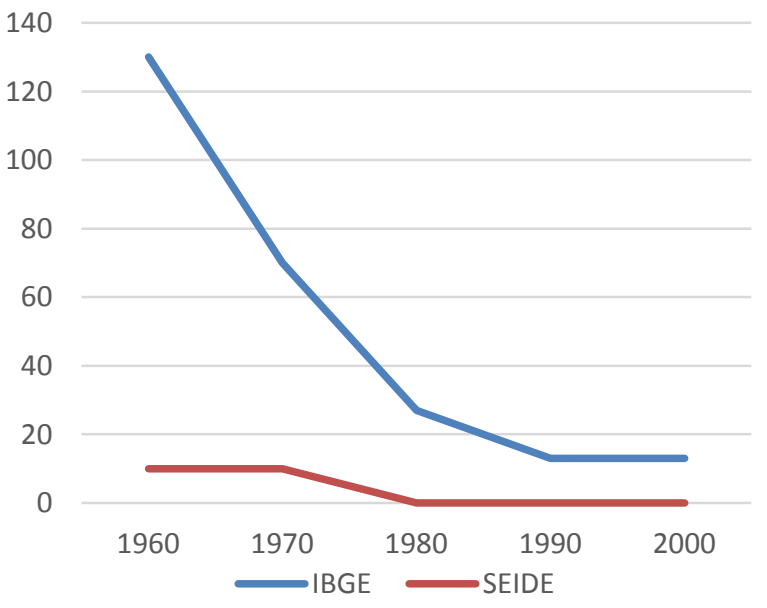

Para o nome Alexandre, não houve di- vergência entre os dados do IBGE e de Seide (2013). Em ambos os casos o auge de utilização ocorre nas décadas de 1980 e 1990, conforme evidencia o Gráfico 3. Como não houve registro de utilização em Seide (2013) e frequência de uso estatisticamente relevante no IBGE. O mesmo fenômeno foi observado na utilização do nome Anderson, conforme se pode verificar no Gráfico 4.

Gráfico 3-Comparação de resultados para o nome Alexandre Graph 3 -Comparison of results for the name Alexandre

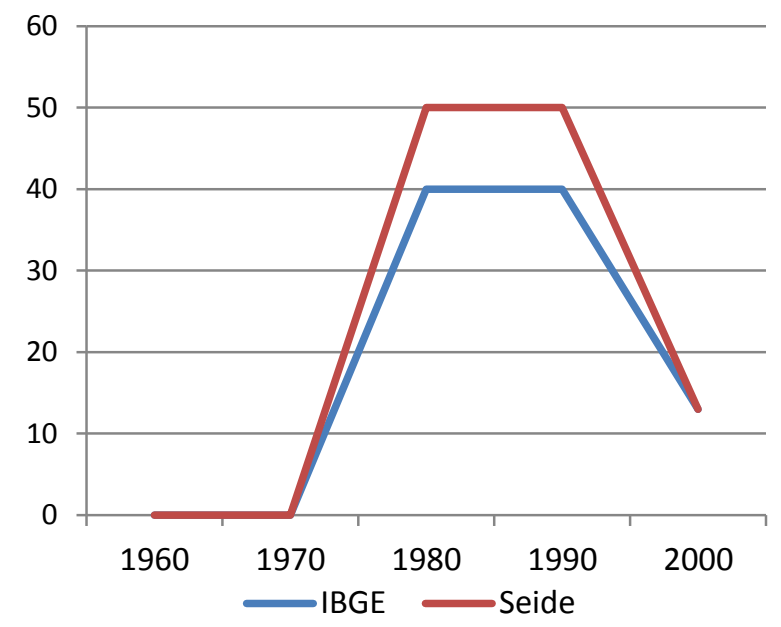

Gráfico 04 - Comparação de resultados para o nome Anderson Graph 4-Comparison of results for the name Anderson

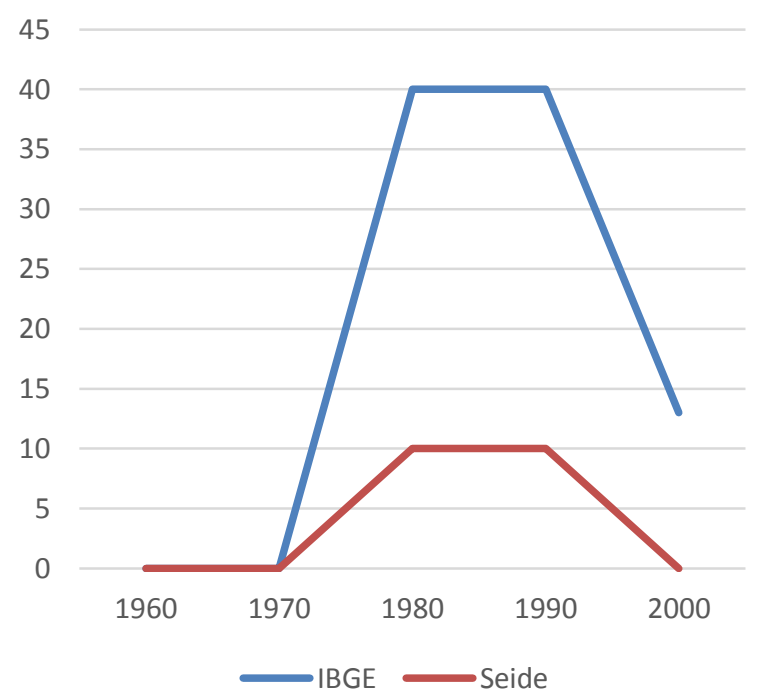

Também houve convergência entre os corpora díspares com relação ao nome Jonatan, em ambos houve um único pico, na 
década de 1990, como se vê no Gráfico 05. Assim como no caso de Alexandre e Anderson, houve coincidência ou concomitância de utilização por residentes e nascidos na região.

Gráfico 5 - Comparação de resultados para o nome Jonatan Graph 5 - Comparison of results for the name Jonatan

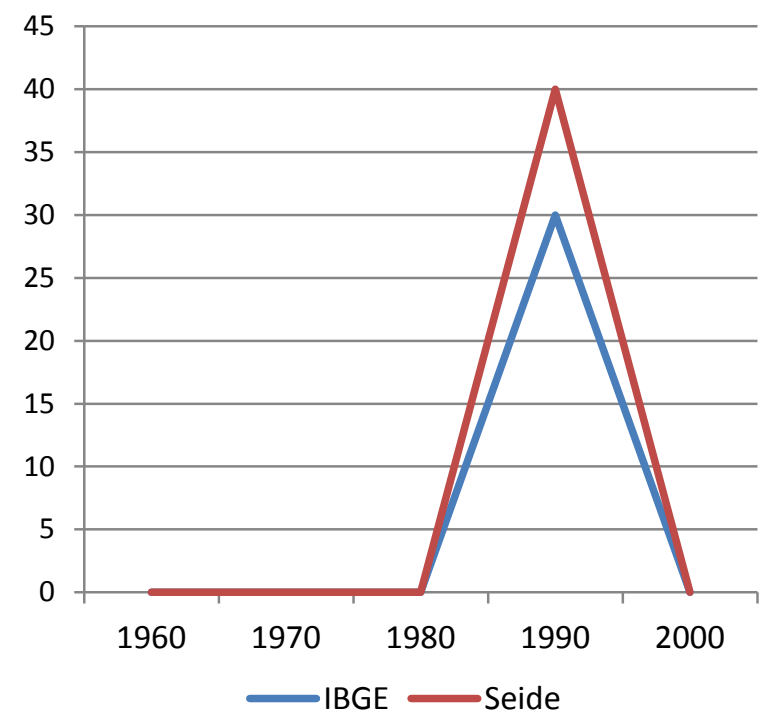

Resultados convergentes também foram encontrados para os nomes Adriano e André. Em ambos os corpora, há um único pico de utilização na década de 1980, ainda que o uso em residentes seja anterior ao uso para os recém-nascidos da amostra em uma década.

Gráfico 6 - Comparação de resultados para o nome Adriano Graph 6 - Comparison of results for the name Adriano

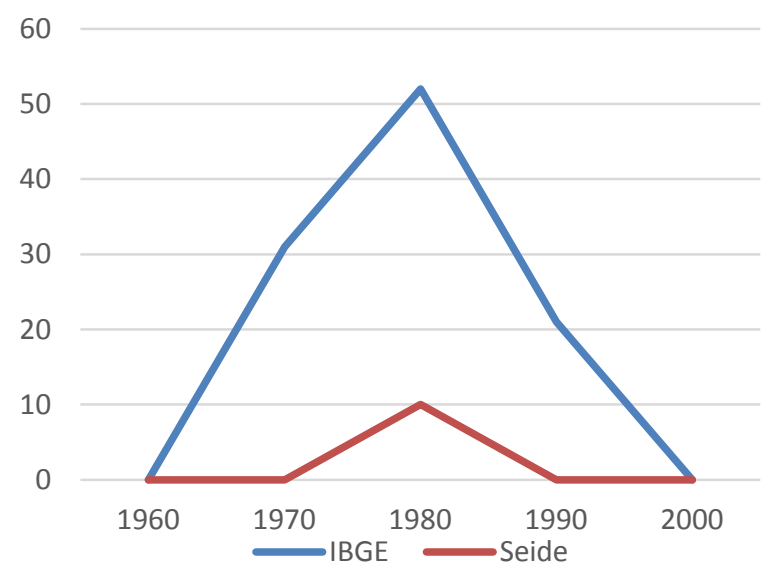

Gráfico 7 - Comparação de resultados para o nome André

Graph 7 -Comparison of results for the name André

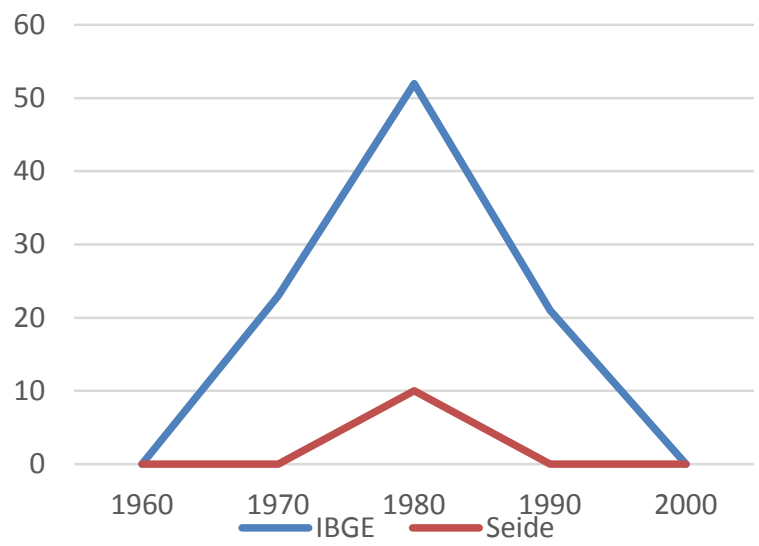

A comparação dos demais nomes necessitaram análises mais detalhadas, nos casos dos nomes Jean, Vinícius e Gabriel, pois o pico de utilização, em pelo menos um corpus, foi registrado na última década do período, 2000. Para o nome Jean, observa-se, no Gráfico 8, que o auge de utilização no IBGE data de 1990 enquanto em Seide (2013) o auge ocorre dez anos depois. O mesmo lapso ocorreu entre o uso em residentes e em nascidos com o prenome Márcio, no Gráfico 09, Rodrigo, no Gráfico 10 e Diego, no Gráfico 11. Para esses nomes, contudo, há convergência na década em que houve diminuição no uso dos nomes.

Gráfico 8-Comparação de resultados para o nome Jean Graph 8 - Comparison of results for the name Jean

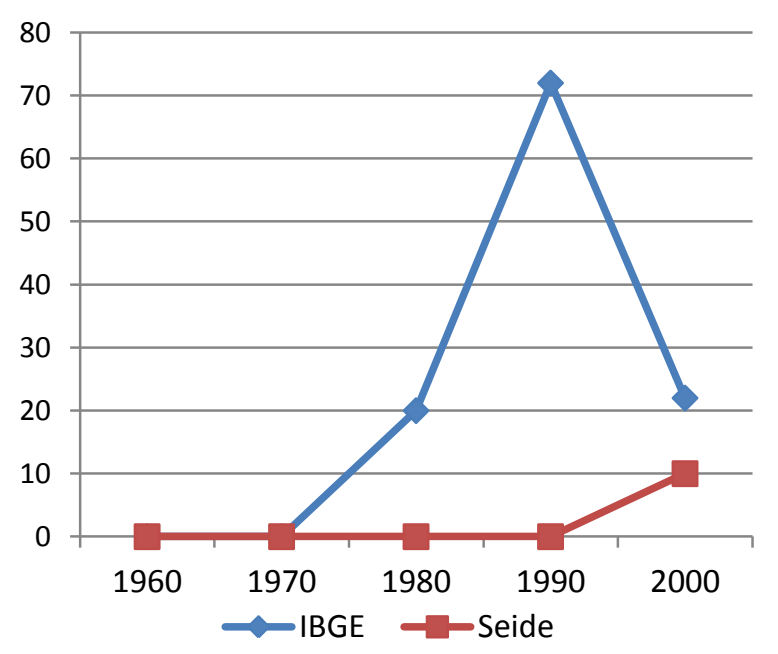

https://periodicos.unifap.br/index.php/estacao Macapá, v. 7, n. 3, p. 83-93, set./dez. 2017 
Gráfico 9 - Comparação de resultados para o nome Márcio Graph 9-Comparison of results for the name Márcio

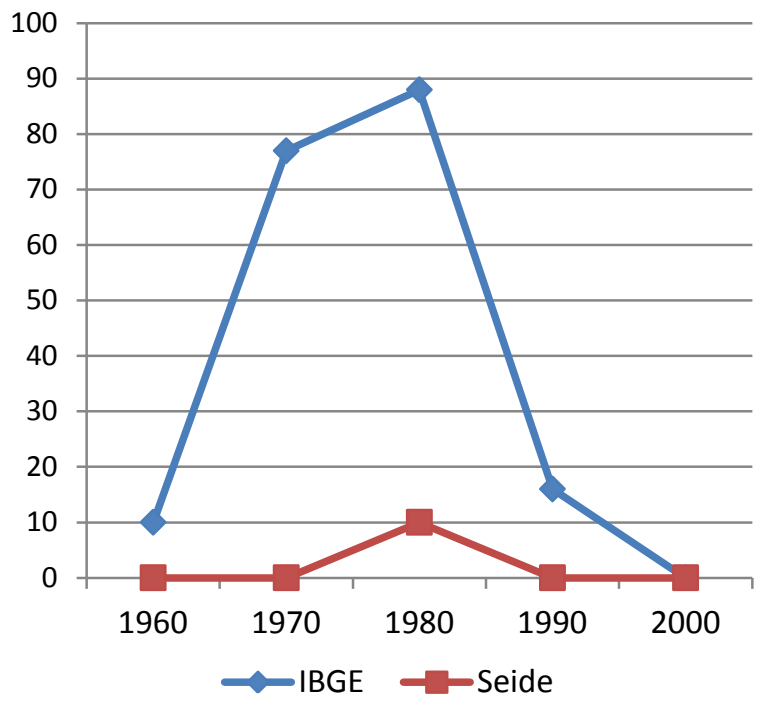

Gráfico 10 - Comparação de resultados para o nome Rodrigo Graph 10 - Comparison of results for the name Rodrigo

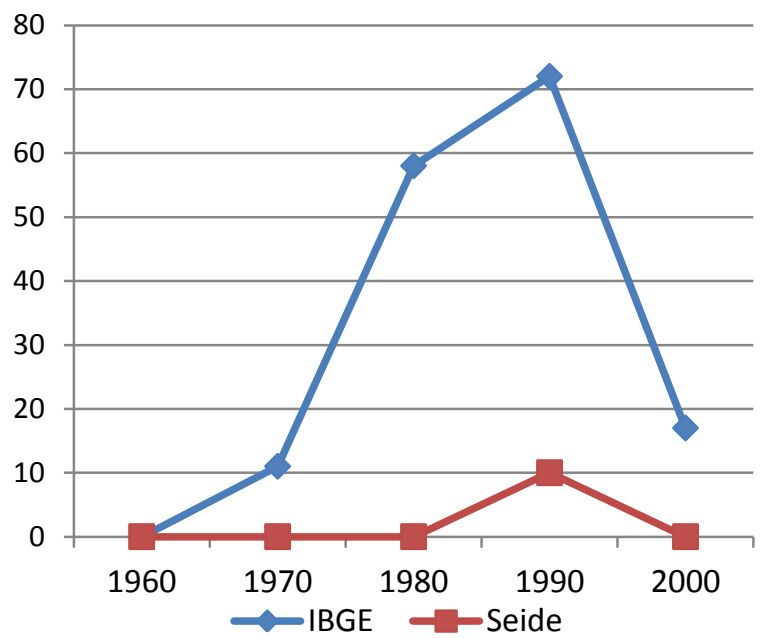

Gráfico 11 - Comparação de resultados para o nome Diego Graph 11 -Comparison of results for the name Diego

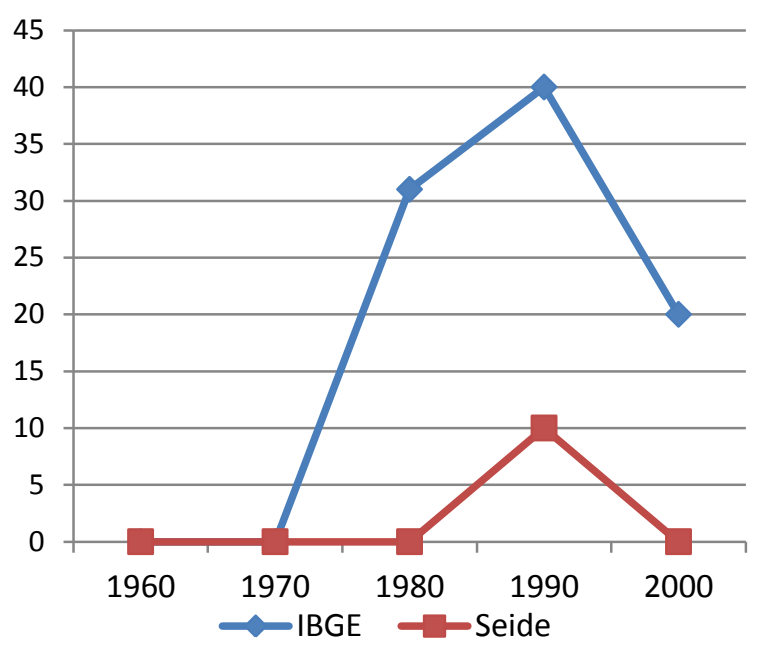

Resultados destoantes foram obtidos para o prenome Augusto, conforme mostra o Gráfico 12. Enquanto, na amostra de Seide (2013), o nome começa a ser usado na década de 1980, no IBGE este nome é registrado na década de 1990 com auge na década seguinte. Este é o único caso em que o auge em recém-nascidos foi anterior ao pico registrado pelo IBGE, resultado que deve ter sido influenciado pelos filtros estatísticos usados década a década.

Gráfico 12 - Comparação de resultados para o nome Augusto Graph 12 - Comparison of results for the name Augusto

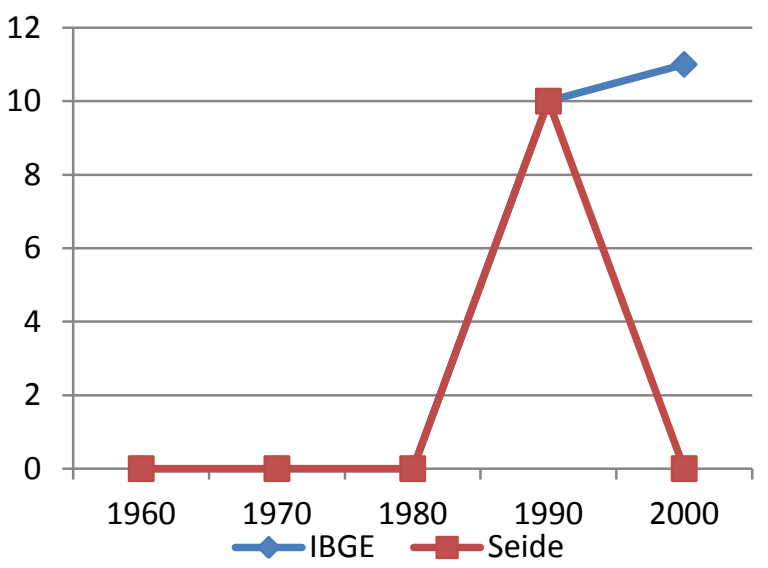

Com relação ao nome Vinícius, no Gráfico 13, em ambos os corpora seu auge de utilização foi registrado na última década do 
período. Enquanto há coincidência no auge em ambos os corpora, apenas no corpus do IBGE houve um auge anterior na década de 1970. Em ambos os corpora, contudo houve lapso temporal de 20 anos entre os auges.

Gráfico 13 - Comparação de resultados para o nome Vinícius Graph 13 - Comparison of results for the name Vinícius

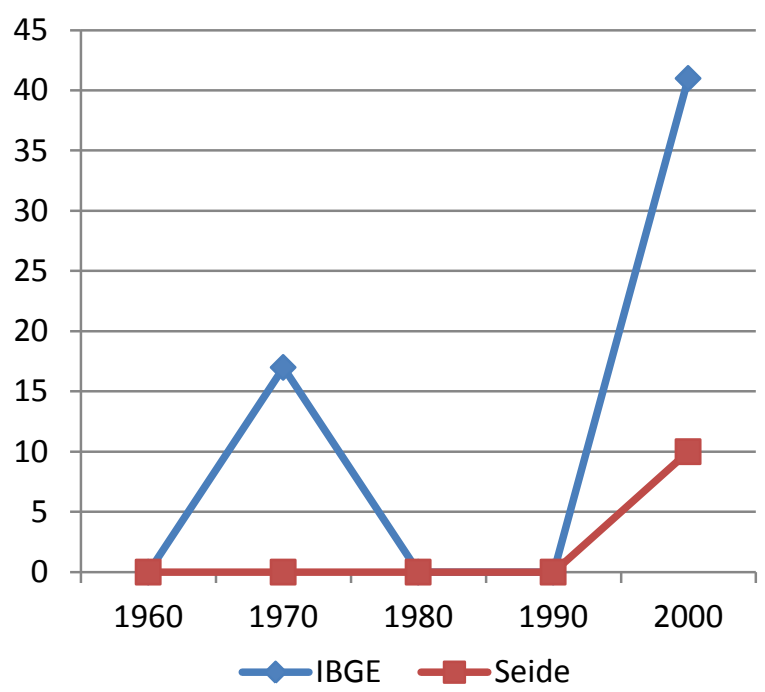

Com relação ao nome Gabriel, o Gráfico 14 mostra que, em ambos os corpora, houve auge de utilização da última década, porém, como nome de residente seu uso já tinha começado a ascender uma década antes, num comportamento semelhante ao verificado para o nome Jean.

Gráfico 14 - Comparação de resultados para o nome Gabriel Graph 14 - Comparison of results for the name Gabriel

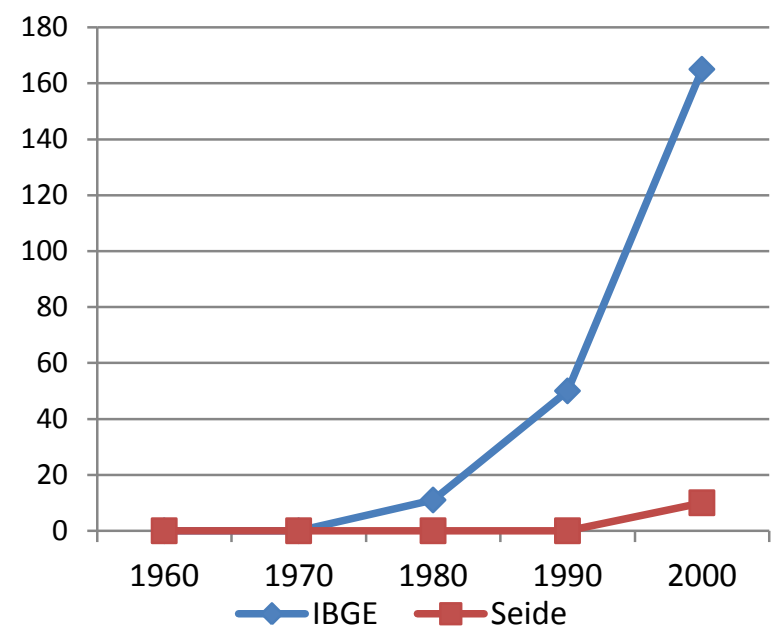

No caso do nome Lucas, houve um pico de utilização na amostra de Seide (2013) no ano de 2000, mas, na amostra do IBGE, o pico foi registrado uma década antes e houve um decréscimo na década seguinte. Analisando-se o Gráfico 15, percebe-se que o ciclo de uso do nome foi bem mais longo no IBGE no período estudado.

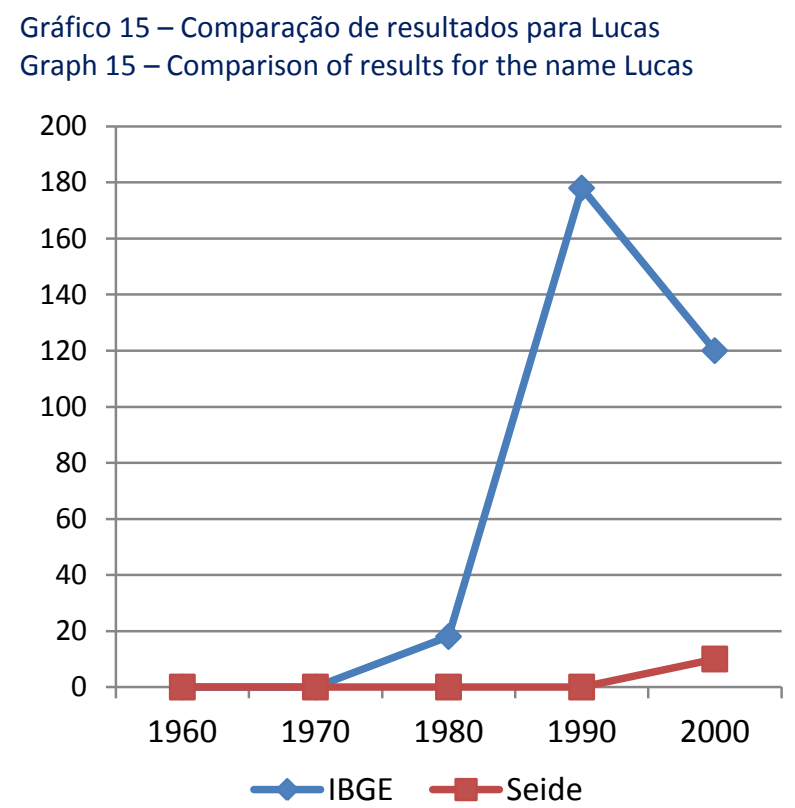

Por fim, com relação aos nomes Marcelo e Marcel é preciso esclarecer que, na amostra do IBGE, houve padronização de variantes morfológicas e ortográficas, motivo pelo qual as ocorrências de Marcel são incluídas no nome Marcelo, inclusão que não ocorreu na amostra de Seide (2013), conforme se observa nos dados visualizados no Gráfico 16, no qual as ocorrências de Marcel são visualizadas com a cor verde e Marcelo com a cor vermelha. Se ambas as formas fossem contabilizadas como Marcelo em Seide (2013), ter-se-ia um auge com dois picos, um em 1980 e outro em 1990. Haveria convergência quanto ao pico e utilização anterior na amostra do IBGE a partir da década de 1960, no entanto, em ambas as amos- 
tras, a última década marca declínio de uso. $\mathrm{O}$ que se pode concluir, portanto, é que o comportamento desse nome é semelhante ao do nome Lucas, com o IBGE registrando um ciclo de utilização mais longo.

Gráfico 16 - Comparação de resultados para os nomes Marcelo, Marcelo e Marcel

Graph 16 - Comparison of results for the name Marcelo, Marcelo and Marcel

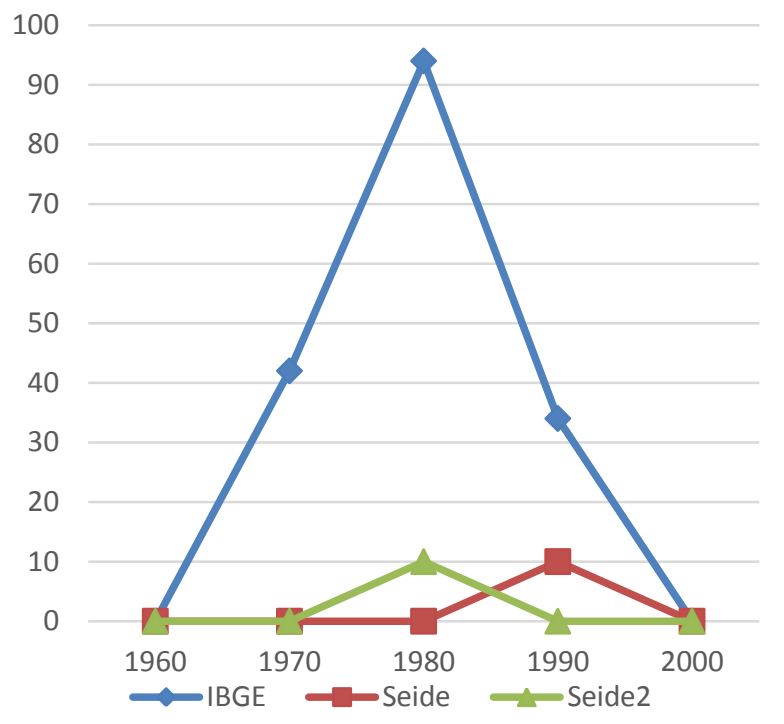

Nessa seção foram apresentados os resultados obtidos pela comparação do comportamento quantitativo dos nomes da amostra de certidões de nascimento (SEIDE 2013) e na amostra do IBGE (2010). Na maioria dos casos, não houve convergência no eixo cronológico, uma vez que a década de auge de utilização dos nomes e de declínio não coincidirem, em ambos os corpora há registro de comportamento semelhante uma vez que, para maioria dos nomes os gráficos gerados visualizam curvas lógicas semelhantes. Isto significa que um corpus diminuto pode ser impreciso, mas pode ser útil ao indicar as tendências de comportamento de uso dos nomes mais frequentes numa dada região, o que possibilita a realização de pesquisas em pequena escala quando se pretende fazer um estudo exploratório sobre dois ou mais sistemas antroponímicos bem como pesquisas comparativas entre comunidades linguísticas com grandes diferenças populacionais.

\section{CONSIDERAÇÕES FINAIS}

Os resultados obtidos relativizam a exigência de que apenas corpora de mesmo tamanho possam ser realmente comparados, haja vista que os gráficos evidenciam um nível razoável de convergência, o que sugere que amostras diferentes, de universos distintos, podem ser usados em análises comparativas desde que sejam feitas as devidas ressalvas quanto à datação precisa de início ou fim de uma tendência de uso. São resultados que legitimam o uso de corpora díspares para análise comparativa de tendências gerais. Espera-se que a investigação ora descrita possa contribuir para um meIhor entendimento de fatores que influenciaram a escolha antroponímica em lugares, comunidades e culturas díspares.

Para além do objetivo inicialmente proposto, os resultados convergentes das amostras apontam para determinadas tendências de uso a seguir descritas. Observo que, dos nomes pesquisados, dois não foram escolhidos pelos pais a partir da década de 1980 quando havia muitos residentes no Município que tinham um desses nomes, isto é, estavam disponíveis no entorno social: Carlos e José. É provável que os pais tenham considerado esses nomes como disponíveis demais, em outras palavras, muito banalizados.

Os nomes Jean e Gabriel, contudo, começaram a ser utilizados uma década depois do seu registro como nome de residente, indicando que estavam disponíveis no 
entorno. Contudo, assim que atingido um auge de uso, foram preteridos em ambos os corpora. Este fenômeno ocorreu com os nomes Adriano, André, Jean, Márcio, Rodrigo e Diego. Estes resultados indicam que há um limite de uso, após o qual o nome passa a ser avaliado negativamente por conta de sua banalização.

Esta atitude de evitar nomes vistos como banalizados foi evidenciada também na escolha de nomes até então indisponíveis em ambos os corpora. No caso dos nomes Alexandre, Anderson e Jonatan, o auge e o decréscimo de uso ocorreram nas mesmas décadas, o que indica não apenas a preocupação pela escolha de nomes vistos como novos ou originais, mas também a atribuição nomes por modismo num ciclo de curta duração.

Outro indício de que os pais dos filhos registrados na amostra de Seide (2013) evitam nomes banalizados está no fato de que, de modo geral, os ciclos de utilização dos nomes são mais longos no IBGE, como se verifica paras os nomes Lucas e Marcelo. A exceção confirma a regra, apenas para o nome Augusto houve um ciclo de uso mais longo em Seide (2013).

Por fim, o nome Vinícius apresentou um comportamento um pouco distinto na amostra do IBGE na qual apresenta dois picos de uso: um na década de 70 e outro entre 1990 e 2000, este segundo pico coincide com o pico da amostra de Seide (2013), mas o primeiro não.

Mesmo deixando sem conclusão a análise do nome Vinícius, a dos demais nomes indicam claramente a influência da disponibilidade na escolha antroponímica dos pais. Considerando o conjunto de nomes e seu comportamento em ambas as amostras, verificou-se que ou um nome é escolhido por ter se tornado disponível, mas não banalizado ou é preterido por ser visto como excessivamente banalizado, outros são escolhidos justamente por estarem indisponíveis no entorno social. Esses resultados sugerem que a disponibilidade dos nomes no entorno social é um fator que influencia a escolha dos nomes no Município. Falta, contudo, investigar se esta influência também ocorre na antroponímia feminina no Município e se a disponibilidade também é fator de influência de escolhas antroponímicas em outras regiões, dentro e fora do Brasil.

\section{REFERÊNCIAS}

ACTES DEL XXIV CONGRÉS INTERNACIONAL D'ICOS SOBRE CIÈNCIES ONOMÀSTIQUES. 2014 Biblioteca Tècnica de Política Lingüística; 11. Barcelona, 2014. Disponível em: <http://www20.gencat.cat/portal/site/Llen gcat/menuitem.b318de7236aed0e7a129d4 10b0c0e1a0/?vgnextoid=da757832aa76741 OVgnVCM1000008d0c1e0aRCRD\&vgnextch annel=da757832aa767410VgnVCM1000008 d0c1e0aRCRD\&vgnextfmt=default $>$. Acesso em: 01 set. 2015

GUDURIĆ, S. Adaptation et transposition des noms propres du Français en Serbe. Actes del XXIV Congrés Internacional d'ICOS sobre Ciències Onomàstiques. Annex. Secció 3, 2014, p. 327-334.

HUSCHKA, D.; WAGNER, G. G. Statistical Problems and Solutions in Onomastic Research -Exemplified by a Comparison of Given Name Distributions in Germany throughout the 20th Century. SOEPpapers on Multidisciplinary Panel Data Research. Berlin, n.332, p. 1-34. Disponível em: <http://www. diw.de/soeppapers>. Acesso em: 24 nov. 2017. 
IBGE. Censo Demográfico 2010.Nomes no Brasil. Disponível em: <http://censo 2010.ibge.gov.br/nomes/\#/search>. Acesso em: 06 maio 2017.

LÓPEZ-FRANCO, Y. G. Comparaison des prénoms attribués en 1970 et 1975 dans deux comunes romanophones: Tlalnepantla de Baz au Mexique, et Montpellier en France. Une approche sócio anthroponymique. Actes del XXIV Congrés Internacional d'ICOS sobre Ciències Onomàstiques. Annex. Secció 5, 2014a, p. 821-832

LÓPEZ-FRANCO, Y. G. Los nombres de Pilla en la década de 1980 en Montpellier,Fracia, y en Tlalnepantla de Baz, Méxicoi, bajo un enfoque socioantroponímico. In: ISQUERDO, A. N., Dal CORNO, G. O. M. (orgs). As ciências do Léxico. Lexicologia, Lexicografia, Terminologia, vol. VII. Campo Grande, MS: Ed.UFMS: 2014b, p.15-38

MUTSUKAWA, M. Phonological and Semantic Gender Differences in English and Japanese Given Names. Els noms en la vida quotidiana. Actes del XXIV Congrés Internacional d'ICOS sobre Ciències Onomàstiques. Annex. Secció 3,2014. p. 370-377.

REOLON, C. A. Colonização e urbanização da messoregião oeste do Paraná 1940-1960. RA'E GA, Curitiba, n. 13, p. 49-57, 2007.

SEIDE, M. S. Moda e tradição na antroponímia de Marechal Cândido Rondon - PR. Caderno de Resumos Expandidos. IX Encontro intermediário do GT de Lexicologia, Lexicografia e Terminologia da Anpoll, 28/08/2013. Disponível em: <http://150. 164.100.248/gtlexNovo/CMS/index.asp?pas ta $=$ gtlexnovo\&path $=201362820928$.asp\&titl e=IX\%20ENGTLEX\%20-\% 20Resumos\%20Ex pandidos>. Acesso em: 09 maio 2017.

SEIDE, M. S. Métodos de pesquisa em Antroponomástica. Domínios de Lingu@Gem, Uberlândia, MG, v. 10, p. 1146-1171, 2016.

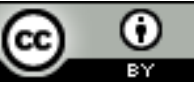

License information: This is an openaccess article distributed under the terms of the Creative Commons Attribution License, which permits unrestricted use, distribution, and reproduction in any medium, provided the original work is properly cited.

Artigo recebido em 10 de novembro de 2017.

Avaliado em 22 de novembro de 2017.

Aceito em 28 de novembro de 2017.

Publicado em 19 de dezembro de 2017.

\section{Como citar este artigo (ABNT):}

SEIDE, Márcia Sipavicius. Comparabilidade de corpora díspares em Antroponomástica Comparada. Estação Científica (UNIFAP), Macapá, v. 7, n. 3, p. 83-93, set./dez. 2017. 